\title{
LA POÉTICA DE ANTONIO GAMONEDA: EL REFERENTE ESOTÉRICO*
}

\author{
JORGE MACHÍN LUCAS
}

The University of Winnipeg

\section{INTRODUCCIÓN}

«¿Que cuál es el espacio de la Lírica? Pues, es el espacio comprendido entre mi memoria poética, el extremo de memoria poética, y el extremo de mi temor, de mi miedo». ${ }^{1}$ Antonio Gamoneda, premio Cervantes del 2006 nacido en 1931, nos anuncia con aquel extracto el itinerario ideológico que va a seguir su cada vez más existencialista y oscura poesía. Esta ha sido separada por la mayoría de la crítica de la

* Recibido: 08-04-2008 Aceptado: 09-06-2008

${ }^{1}$ En F. Martínez García, Gamoneda, una poética temporalizada en el espacio leonés, León, Universidad de León, 1991, p. 34. 
generación de los 50, a la que se la ha adscrito por la naturaleza de sus intertextos: Perse, Trakl, Lorca, los surrealistas, etc. ${ }^{2}$ La lírica del asturiano, criado en Castilla, se extiende desde el recuerdo melancólico y frustrado de una infancia triste, marcada por la vesania de la guerra civil española, hasta la muerte. Como él mismo nos dice «[...] la memoria es siempre conciencia de pérdida [...], de consunción del tiempo correspondiente a mi vida y, por esto mismo, conciencia de ir hacia la muerte». ${ }^{3}$ Ese óbito, con mucho escepticismo, le gustaría que se convirtiera en un renacimiento moral del ser humano en un pasado ideal más allá de la historia. De todos modos, no se establece un programa social, sino uno simplemente regenerador en lo ético y moral. Nos encontramos ante un poeta laico que es deudor de una larga tradición ontológica de autores que fueron en busca de un pasado inexistente y depurado para tratar de reformar desde la lírica y la interiorización la injusta historia que les tocó vivir. Estamos en la era de la «indetermanencia» según Ihab Hassan. ${ }^{4}$ Este crítico propone una mirada sin ilusión personal ni colectiva y con mucha indeterminación hacia el interior del ser humano, lo inmanente. Ella pretende superar una obvia crisis de valores de lo histórico en unos siglos XX y XXI marcados por la ruindad de las luchas por el poder y sus devastadores efectos. Pedro Serrano lo resume así con respecto a Gamoneda: «Sus poemas son fotografías exactas de la miseria y lo inmisericorde, y de una voluntad de vida que florece a pesar de la opresión y en la opresión». 5

Así pues, su lírica dialoga con una secuencia literaria que va en busca del origen del ser y de la vida como evasión de una realidad agria y como intento utópico de redención humana. En su naturaleza está el aliento postromántico en pos

\footnotetext{
${ }^{2}$ Estas filiaciones se encuentran en L. García Jambrina (ed.), La promoción poética de los 50. Ángel González, José Manuel Caballero Bonald, Carlos Barral, José Agustín Goytisolo, Jaime Gil de Biedma, José Ángel Valente, Francisco Brines, Claudio Rodríguez, Madrid, Espasa Calpe, Colección Austral, 2000, p. 24.

${ }^{3}$ En A. Gamoneda, El cuerpo de los símbolos, Murcia: Huerga y Fierro, 1997, p. 24

${ }^{4}$ En The Postmodern Turn: Essays in Postmodern Theory and Culture, Columbus, Ohio State University Press, 1987, p. 91.

${ }^{5}$ En «Gamoneda: la escasez y la necesidad», Letras Libres, 84 (2005), p. 85.
} 
de una quimera del ser y de la palabra hacia lo primigenio. Está hecha desde tropos que en su representación ilógica de lo no contingente de la personalidad humana le acercan más a la órbita del surrealismo de un Larrea, Vallejo o Westphalen y del creacionismo de un Huidobro. Esa deuda se deja ver en la imagen onírica y en el rapto alucinatorio que también tuvieron los místicos. Así lo expresa el mismo Gamoneda: «La palabra “trascendencia” me da mucho miedo: no sé manejarla. En mi trabajo poético puede haber contaminación de lenguaje religioso, pero no convicciones. No soy hombre religioso aunque pueda estar habitado por voces religiosas». 6

Con su influencia inhibe los mecanismos pretendidamente cognitivos y racionales del yo para llegar a manifestar la verdad pararracional y emocional del yo lírico. Para él, la palabra es más importante que lo referencial, mimético y representativo hacia un discurso autorreferencial, semiótico y simbólico. Debicki lo llama «poesía de descubrimiento», aquella que forja nuevas visiones desde el uso creativo de un lenguaje de a diario, de acontecimientos anecdóticos y de evocaciones personales. ${ }^{7}$ También el mismo crítico la califica de «esencialista» y sitúa su apogeo en los años $80 .{ }^{8}$ Esta poesía estaría según Silver en esa tradición dual española de «relación ambigua con la realidad» y de «curioso movimiento de atracción hacia los objetos naturales a la par que de repugnancia ante ellos». ${ }^{9}$ Es decir, el poeta parte del campo de lo real para representar de manera comprensible lo surreal. Por su parte, Fernando Castro ha denominado su obra como «[...] [c]anto del origen y de la soledad», en clara alusión a esa introspección en el mundo, en la otredad y en el yo. ${ }^{10}$

\footnotetext{
${ }^{6}$ A. Gamoneda, op. cit., p. 173

7 En A. Debicki, Poetry of Discovery: The Spanish Generation of 1956-1971, Lexington, Ky, The University Press of Kentucky, 1982, p. 18.

${ }^{8}$ En A. Debicki, Historia de la poesía española del siglo XX: desde la modernidad hasta el presente, Madrid, Gredos, 1997, p. 259.

${ }^{9}$ En P. Silver, La casa de Anteo: Ensayos de poética hispana (De Antonio Machado a Claudio Rodríguez), Versión española de Salustiano Masó, Madrid, Taurus, 1985, p. 46.

10 En F. Castro Flórez, «Manos de tierra» en AAVV, Antonio Gamoneda, Madrid, Calambur, 1993, p. 36.
} 
El ovetense, formado en León, ha negado insistentemente que su obra se inscriba dentro de las tradiciones místicas canónicas. La verdad es que él quiere advertirnos de su desvinculación de un mensaje de orden teofánico o estrictamente religioso. La mística habla de una relación individual del hombre con la divinidad y ese nunca ha sido su propósito ni en lo vital ni en lo poético. Este pensamiento no sigue las reglas de lo religioso y da libertad al examen personal de la muerte y de la posibilidad de lo trascendente. No cabe duda de que esta poesía trata de buscar esa trascendencia irreal e imposible de la que se duda con un modelo similar pero invertido hacia una exploración inmanente. Dicha inversión consiste en que vamos de la exaltación de lo divino a la de la ipseidad y a la de la creación de la vida. Además, es palmaria su simpatía hacia la izquierda, el compromiso hacia el materialismo sociohistórico (véase la admiración e influencia hacia el poeta comunista turco Nazim Hikmet) y un innegable pesimismo en el porvenir de la humanidad y, por extensión, del ser humano como ente concreto.

No obstante, ciertas problemáticas que se encuentran en su obra poética van a incidir en ciertos temas recurrentes en la denominada «poesía del silencio» de innegables tonos esotéricos. El poeta, según Mayhew, se erige en un demiurgo, transformándose «[...] from a concrete historical individual into a transcendent force». ${ }^{11} \mathrm{Su}$ obra acaba convirtiéndose en una mística revertida hacia lo profano si se evalúan ciertas ideas e imaginería que usa. Por ejemplo, la figura de Dios aparece en su obra entre la decadencia del ser y del ambiente degradado que le rodea. Esta figura es enunciada con una «d» minúscula que evidencia su agnosticismo y la creencia de que no hay una divinidad que nos una a todos, sino sólo los dioses particulares que nos creamos a causa del miedo al sufrimiento y a la desaparición total con la muerte. De acuerdo con Manuel Vilas, la teosis en su poesía «está cargada

\footnotetext{
${ }^{11}$ En J. Mayhew, «Rhetoric and Truth in Gamoneda», in The Poetics of Self-Consciousness. Twentieth Century Spanish Poetry, Lewisburg, Bucknell University Press, London and Toronto, Associated University Presses, 1994, p. 89.
} 
de un simbolismo negativo; es como si el dolor humano sepultase también la esperanza divina». .12

Gamoneda está unido a una amplia corriente que en este siglo ha penetrado, con mayor o menor calado, en la literatura hispánica en las obras de Carlos Bousoño, Octavio Paz, José Lezama Lima, María Zambrano y Clara Janés, entre otros. Y sobre todo está vinculado a la de su amigo José Ángel Valente, la más directa. Por ejemplo, hay unas actitudes de «escepticismo», «ataraxia»y «preparación ascética» frente a una caediza realidad que le unen a Valente para Amelia Gamoneda y Fernando R. de la Flor hacia un «éxtasis final "blanco"» en el «momento en que el sujeto ha culminado su trabajo de reconstrucción de sí mismo».13 De hecho, Jorge Rodríguez Padrón lo ve como una «mística del revés: descenso [...] hasta la verdad que es mentira habitual».14 Como veremos, en el caso de este último, hay un escepticismo materialista y un sentido agnóstico en el itinerario de Gamoneda que se detiene mucho antes de que se pueda atisbar esa unión personal que se producirá en el centro de la ipseidad con la esencia de lo originario que formó lo cosmológico y al ser.

Él mismo reconoce lo siguiente en su estudio sobre Valente: «Creo que permanezco en un materialismo visionario y en un agnosticismo pasivo. Sin embargo, yo me he acercado también a la luminosidad del no ser, o mejor, la he atraído hacia mí (...)». 15 Por otra parte, considera que la crítica ha situado al gallego «en un orden metafísico y hasta místico» y a él mismo en el «hermetismo e irracionalismo», algo que niega ya que lo irracional no puede generar la lógica de un

\footnotetext{
12 En M. Vilas, «La muerte, y su hermano el miedo: la "edad" de Antonio Gamoneda» en AAVV, Antonio Gamoneda, Madrid, Calambur, 1993, p. 52.

${ }^{13}$ En A. Gamoneda y F. R. de la Flor (eds.), «Preliminar» en Sílabas negras, Salamanca, Ediciones Universidad de Salamanca y Patrimonio Nacional, 2006, p. 59 y nota 110.

${ }^{14}$ En J. Rodríguez Padrón, «Desnudo ante el agua inmóvil» en AAVV, Antonio Gamoneda, Madrid, Calambur, 1993, pp. 135-144, p. 140.

${ }^{15}$ En A. Gamoneda, Valente: texto y contexto. Santiago de Compostela, Universidade de Santiago de Compostela, 2007, p. 66.
} 
poema. ${ }^{16}$ De todos modos, ambas actitudes, desde dos ángulos opuestos, convergen en ese punto de aislamiento de la historia hacia un origen situado en lo que se puede denominar como un archipretérito o pasado ideal, arquetípico. Allí, desde el útero materno, se podría reconstituir una nueva Historia con «H» mayúscula, un nuevo ser y un nuevo logos. Es un retorno pagano hacia una naturaleza matriz que, como bien advierte Juan Carlos Mestre, representa «la pasión mística y romántica de una voluntad tan próxima a la herejía como al panteísmo».17 El uso de vocabulario que alude a lo fronterizo de los «bordes» o «límites» entre la vida y la muerte, o de animales, de plantas y de líquidos taumatúrgicos que simbolizan la descomposición de la identidad, de pájaros espirituales, de «dioses» individuales, de niños que van en busca de su madre, de olvidos, de fulgores, de vértigos, de quietudes, de transparencias y de silencios, así como alusiones a la pintura abstracta y a un paratexto de resonancias esotéricas de Lezama Lima que dice que «la luz es el primer animal visible de lo invisible» (en Material Memoria de Valente de 1977 y en la más reciente Cecilia escrita entre 2000 y 2004 por Gamoneda) son algunos de sus incontables parecidos que los entroncan.

Pero volviendo a nuestro autor, huelga decir que existen ciertas topografías literarias por las que discurre su obra. El punto de partida es un alejamiento de la historia real, fenoménica, injusta, ascética. Posteriormente, se adentra en una ultrahistoria o historia interior, psicológica, alienada, iluminativa, del ser en búsqueda de sí mismo. Y finalmente, pretende ir hacia esa nueva Historia gnoseológica, ilusoria, unitiva, que se detiene en los albores de la muerte sin apenas esperanza de eternidad. Es un viaje interior en busca del amor humano más allá de la muerte. Como nos advierte Antonio Colinas: «Toda la obra de Gamoneda es como

\footnotetext{
${ }^{16}$ Ibidem, p. 67.

17 En J. C. Mestre, «Sublevación inmóvil» en AAVV, Antonio Gamoneda, Madrid, Calambur, 1993, pp. 87-94, p. 90.
} 
una soterrada batalla entre la crueldad de la realidad y la ternura humana», usando el tema de España sin la retórica fácil de posguerra. ${ }^{18}$

Su obra, así pues, se propone evadirse de lo real yendo a lo que Lyotard llamaría el sublime, la expresión postmoderna de lo inefable. ${ }^{19}$ Lamentablemente, el poeta no cree que haya nada más allá del último estado del ser en el tiempo, la muerte, aunque lo desearía. La única posibilidad factible de redención es la perpetuación a través de la palabra. Esta continuidad y evolución de la vida van ligadas al intento de buscar un significante que posea la plenitud de los significados en su interior y que redima a los humanos. Él está más allá del «umbral», de los «límites» o «bordes», palabras que prefiguran la separación entre la vida y la muerte, entre el eros y el tánatos, el ordo amoris y el ordo tremoris. Es un nuevo espacio, entre lo rural depurado y lo interior, y un nuevo tiempo, el que se proyecta hacia la muerte desde un retorno a una infancia idealizada. Ambos vectores están incardinados en una premodernidad estetizada en la que el ser y el mundo todavía no se habían constituido. Desde allí se debe recomenzar la historia sin cometer los pasados errores y alcanzar una «justicia» de carácter social que una de nuevo al hombre con el mundo y con su arkhé. ${ }^{20}$ Esa es la nueva Historia ideal, una ilusión de comunión, de solidaridad, de salvación y de eternidad humanas.

$\mathrm{Ni}$ que decir tiene que esta llegada al momento de la generación telúrica de la vida es para él una vuelta a la madre. Ella tiene un significado dual: la biológica y la panteísta de la creación de lo cosmológico, de lo natural, de los seres y del yo lírico. Lo plasma en sus versos con un doble motivo: para dejarlos con la intención de que los recojan las siguientes generaciones y para conjurar un quimérico estado de depuración de la agonía anterior a la muerte. Ese es el de una nueva vida que se

\footnotetext{
${ }^{18}$ En A. Colinas, «Lápidas, de Antonio Gamoneda: un humanismo para el fin de siglo», Ínsula, 487 (1987), p. 17.

${ }^{19}$ En J. F. Lyotard, The Postmodern Condition, 1979, Translated from French by Geoff Bennington and Brian Massumi, Minneapolis, University of Minnesota Press, 1993, pp. 78-81.

${ }^{20}$ En J. C. Suñén, «La expresión de un deber desconocido (Poesía y conciencia en Blues castellano)» en AAVV, Antonio Gamoneda, Madrid, Calambur, 1993, p. 100.
} 
desea que se repita con más armonía y que conlleva un nuevo conocimiento que se representa a través de lo fragmentario, en cuyos intersticios parece hallarse un saber que la articulación convencional del lenguaje y del discurso se resisten a captar. A falta de un conocimiento total, ese saber se puede mostrar discursivamente sólo de manera limitada en su multiformidad. Esta poética asume la imperfección de los humanos para llegar a codificarlo, así como que lo racional es tan sólo un débil intento de manifestar lo real. Por ende, lo irracional se erige como una ampliación, no como una subversión, epistemológica del conocimiento convencional e institucionalmente aceptado. Si se apela a una nueva realidad, que está más allá de lo sensorial y que es sólo representable desde el orden simbólico y metafórico, y que los hombres son imperfectos para alcanzar el conocimiento pleno, con razón se entiende que esa palabra matriz se debe hallar más allá del sonido que pueden percibir, tal vez traspasados los límites del silencio, que para Gamoneda es «[...] el espacio de la memoria, el de la duda, el del miedo... [...] es un modo de existir». ${ }^{21}$

Esta dialéctica entre lo exotérico, la realidad común visible, y lo esotérico, la realidad interior invisible, ha existido a lo largo de todos los tiempos, aunque adaptada a la estética postmoderna de la que Gamoneda es heredero. A saber, se trata de una recuperación a través del recuerdo impostor de una historia en descomposición para sublimarla con una vuelta a un origen depurado. De hecho, volver la mirada hacia el pasado ha sido la constante que ha detectado Fredric Jameson en lo formal y en lo coyuntural en la postmodernidad del tercer tercio del siglo XX. Es obvio que el crítico estadounidense cree que esa vuelta a la historia, producto de la saturación de la novedad propia de la era moderna, recupera de una manera tan impostada el pasado que lo hace desaparecer tal y como era para depurarlo estéticamente según los gustos del presente. Así lo enuncia: «In the

\footnotetext{
${ }^{21}$ En A. Gamoneda, op. cit., p. 184.
} 
postmodern, then, the past itself has disappeared (along with the well-known "sense of the past" or historicity and collective memory)».22

En el fondo, eso es lo que hace Gamoneda, apropiarse del pasado para depurarlo en su peculiar y pesimista estética de la muerte. Absorbe esa tradición mística, la desmitifica, la humaniza y la reencamina hacia lo profano. Quiere con ello representar esta unión de los seres aquí en la tierra, que se augura imposible en la realidad. Este es un intento corrector de los excesos de la postmodernidad en cuanto a la alienación del ser, a los abusos de poder, al materialismo, al consumismo y al hedonismo. Es un itinerario que va del yo y del tú separados por el individualismo y el egoísmo a la solidaridad del nosotros y finalmente a la unificación del yo recompuesto. También es un desplazamiento de lo real a lo autorreferencial y de la necesidad del recuerdo con la memoria al miedo hacia el deceso futuro pasando por el eje axial que componen el binomio «verdad» $\mathrm{y}$ «mentira» en su obra maestra Descripción de la mentira (1975-6 y 2003). En su poética implosiona la confianza en el progreso y ese optimismo se convierte en negatividad hacia lo fútil del ser humano y de su identidad. Nuestro poeta considera que todos los intentos de evolución humanos dictados por el racionalismo se dirigen primero hacia la entropía y luego hacia la nada más absolutas.

En pocas palabras, es un yo lírico cuya identidad reside en el «tormento» frente «a una nada que se sufre, a un dolor que aniquila» de acuerdo con Diego Doncel. ${ }^{23}$ Él emprende un viaje melancólico de lo utópico, la búsqueda de la justicia social absoluta, a lo universal, la reintegración del hombre con el cosmos. Bajo esta actitud subyace un sentimiento íntimo de fracaso personal y de incapacidad de regeneración ética y moral. La crítica a la injusticia se convierte en crisis personal y se abre en una estructura trimembre. Primero la agnosis, el descubrimiento de un

\footnotetext{
22 En F. Jameson, Postmodernism, or, The Cultural Logic of Late Capitalism, Durham, Duke University Press, 1991, p. 309.

${ }^{23}$ En D. Doncel, «Las experiencias de Antonio Gamoneda» en AAVV, Antonio Gamoneda, Madrid, Calambur, 1993, p. 13.
} 
problema identitario y su consiguiente purgación para depurarse en esa historia convencional. Segundo, la crisis hacia una iluminación verbal y lógica en esa interiorización o ultrahistoria. Tercero y último, el fallido intento de alcanzar esa catarsis inmanente y esa unión frustrada con la madre en el pasado ideal de la gran Historia del ser. Es el itinerario canónico de la mística cristiana desde una visión agnóstica ante el imperio destructor de la muerte.

Hay que destacar que hay tres vectores que unidos forman el cañamazo estructural de su viaje poético y ontológico en espiral hacia esa nada que los místicos veían como un estado de unidad y de plenitud del ser consigo mismo y con el cosmos. Se expresaba desencarnando la palabra hasta alcanzar los máximos niveles de depuración en el significante y en el significado que nos permite el lenguaje convencional. Es una doble actitud entre lo órfico, la prospección en el ser, y lo hermético, la que se produce en el lenguaje, según Gerald Bruns. ${ }^{24}$ El primer vector es la paulatina depuración de los modos de la historia gobernados por un silente «dios» en minúscula. Son representados por las nociones de tiempo y de espacio hacia ese pasado arquetípico de la humanidad. Desde él se pudiera reconducir la historia referencial hacia una Historia ideal. Ello se produce a través del solipsismo o ultrahistoria del ser. El segundo es el proceso de depuración de la palabra en busca de un nuevo logos que defina y redima el nuevo mundo y ontos, el ser. El tercero lo constituyen sus ideas de un proceso nostálgico hacia el origen representado por la vuelta a la madre biológica y a la natural. La conclusión, derivada por síntesis de las anteriores ideas, es que se trata de un proceso de evasión frente al materialismo moderno y de recuperación de la igualdad humana desde una ética y una estética místicas en las que el auténtico eje es el descubrimiento del fracaso de la vida en la muerte.

\footnotetext{
24 En Gerald Bruns, Modern Poetry and the Idea of Language: A Critical and Historical Study, New Haven and London, Yale University Press, 1974, pp. 1-7, 232-262.
} 


\section{MODOS DEL «DIOS» INDIVIDUAL, DE LA HISTORIA, DEL TIEMPO Y DEL ESPACIO EN EL YO LÍRICO}

Según Álvaro Valverde este proceso en la obra de Gamoneda es un «[s]ilencio de la vida y silencio de la muerte que halla un correlato en el más duro silencio de Dios». ${ }^{25} \mathrm{Su}$ obra es una búsqueda inmanente que suple a un «dios caído en el dolor», «inmóvil» (vv. 2, 5), ${ }^{26}$ que está «sucio de profecías» (v. 6) ${ }^{27}$ y que es «fugitivo» (v. 4) ${ }^{28}$ cuyas únicas manifestaciones son la nada, el vacío y la desesperanza. Por tanto, aunque lo anhele, el componente trascendente, la mística convencional, no existe. Para elaborar este discurso abstracto que represente a esta divinidad no eterna en el centro del ser, se construye un discurso autorreferencial saturado de símbolos y de metáforas para mostrar la gnosis. Se puede decir que es una mística reflexiva, del sujeto lírico hacia sí mismo, en su interior. El «peregrinaje vital en busca de la luz» que ve Pérez Lasheras es en la inmanencia. ${ }^{29}$ La única dirección hacia la que nos lleva este viático interior es la muerte, depurada y estetizada como la deseada antesala de un origen que se resiste a existir. Gamoneda está en la línea de un Martin Heidegger que veía que el tiempo es un «estar vuelto hacia la muerte» en la historicidad del ser. ${ }^{30}$ Así nos dice: «[...] mi comprensión de la vida consiste en una memoria mortal y en una perspectiva mortal, aunque no excluya el amor a la vida, ni el placer». ${ }^{31}$

La vida es un transcurso amargo por la historia convencional: su pupila lírica se detiene en la memoria, en las catastróficas consecuencias de la guerra civil

\footnotetext{
${ }^{25}$ En Á. Valverde, «La travesía del silencio (Pasión de la mirada)» en AAVV, Antonio Gamoneda, Madrid, Calambur, 1993, p. 105.

${ }^{26}$ En A. Gamoneda, Esta luz: poesía reunida (1947-2004), Epílogo de Miguel Casado, Barcelona, Galaxia Gutenberg-Círculo de Lectores, 2004, p. 43.

27 Ibidem, p. 47.

${ }^{28}$ Ibidem, p. 74.

${ }^{29}$ En. A. Pérez Lasheras, «De la juventud del dolor a la frialdad de la existencia: la poética unitaria de Antonio Gamoneda» en Luis Beltrán Almería y Juan Carlos Pueo (eds.), Actas del Congreso Jaime Gil de Biedma y su generación poética, Vol. II, Zaragoza, Diputación General de Aragón, 1996, p. 660.

${ }^{30}$ En M. Heidegger, Ser y tiempo, Traducción, prólogo y notas de Jorge Eduardo Rivera C., Madrid, Trotta, 2003, p. 402.

31 En S. Martínez, «Antonio Gamoneda: "La poesía sirve para nombrar lo desconocido".», Lateral, 83 (noviembre 2001), p. 9.
} 
española sobre los humanos y en la injusticia social en general. La ultrahistoria, o proceso solipsista, es manifestada a través del paso de la verdad oficial a la mentira ideal con la evocación de las figuras del padre y de la madre en Descripción de la mentira. Esa mentira es el nuevo discurso que nos debiera de abrir un nuevo saber en los albores de la muerte. Es una apertura epistemológica de la insuficiente razón convencional. Aun así, como ella va más allá de todo discurso racional, sólo se puede manifestar a través de imágenes que representen el silencio, donde está ese saber total que la imperfección de los humanos no puede percibir. Si consideramos que más allá de la materia pudiera estar la realidad posterior a la muerte, su expresión debiera estar en el ultrasonido, en el espacio del silencio. Como salvación frente a la incapacidad de aprehender esta otra realidad se centra en las figuras de la madre, del padre ausente que germinará su vida entre sus piernas, del origen global del mundo y de la vida en esa Historia ideal que se duda que se vaya a producir de verdad.

Para articular el contexto cronotópico de este itinerario, Gamoneda se vale de una diversidad de tiempos que expresan lo proteico de este proceso interior. Él mismo los enumeró en ocho del siguiente modo, de una manera más intuitiva que reflexiva. Por un lado, para el poema, primero el gramatical o de la sintaxis; segundo el físico, el que materializa en la historia el acto de escribir el poema; y tercero el de la conducta, la dimensión oral, la estructura musical. Por otra parte, para el poeta se ven el de la memoria del pasado, el del miedo al futuro y el que supone la confluencia de los dos en el momento de la contemplación en ese presente que «fugit irreparabile», que huye para siempre. ${ }^{32}$ También, según él, en el propio discurso se pueden implicar el futuro y el pasado. ${ }^{33}$ Lo que parece claro, de manera mucho más sintética en cuanto a lo ideológico, es que se evoluciona de un tiempo que mira hacia un pasado traumático, el histórico de la posguerra, a otro que mira hacia un futuro desolador, el de la muerte, que se desearía que llevara a los humanos a un pasado

\footnotetext{
32 En F. Martínez García, Gamoneda, una poética temporalizada en el espacio leonés, León, Universidad de León, 1991, p. 40.

${ }^{33}$ Ibidem, pp. 40, 46.
} 
ideal en el origen. Por añadidura, en su obra poética el espacio se va diluyendo desde uno de soledad y de desasosiego interior frente a la realidad y a los recuerdos hacia un tú amatorio, y de búsqueda baldía de reconciliación con el ser humano, hasta otro luctuoso y autorreferencial: «Hay úlceras en la pureza, vamos/ de lo visible a lo invisible». ${ }^{34}$ Estos versos nos muestran los estratos interiores de un ser que se descompone hacia un pasado y un conocimiento ideales que desembocan en la muerte. Finalmente, la nieta del poeta, Cecilia, le descubre un nuevo amor a las puertas de la extinción y de los reinos de lo invisible. Estas categorizaciones espaciotemporales se podrían sintetizar así en este viaje interior del ser hacia la nada.

En sus Primeros poemas: la tierra y los labios (1947-1953 y 2003) se articulan un tiempo y espacio que son configurados por una mente evocativa, llena de soledades por las ausencias del padre y las desapariciones de la guerra. Esa se define por un pasado de frustraciones amatorias hacia un tú no especificado. El tiempo se proyecta hacia un presente congelado en el dolor que tiene premoniciones de un futuro predeterminado por un destino de muerte. Así pues, se prevé que el yo lírico se convertirá en un homo viator hacia la desaparición en el fondo de su mente o inmanencia. Sublevación inmóvil (1953-1959 y 2003), que para Valverde «va de lo real o exterior $[\ldots]$ a lo simbólico o interior $[. .$.$] », nos muestra ese «dios» íntimo en$ minúscula que se encuentra en la inmovilidad del centro del yo. ${ }^{35}$ Él es la estación de término de este viaje interior. A él le lleva su desconfianza y frustración ante la historia y el dolor producido por la pérdida de la alteridad en forma de un amor. La presencia de los espacios rurales en su tercera parte recupera las esencias de un pasado que vuelve hacia el presente congelado y deformado por una memoria que adultera, recrea e idealiza lo vivido. El tiempo mental sigue en este proceso de desplazamiento desde ese pasado agónico hasta ese futuro de aniquilación pasando por un presente referencial que no evoluciona. Es allí donde sitúa su discurso poético

\footnotetext{
${ }^{34}$ En A. Gamoneda, op. cit., pp. 4-5.

${ }^{35}$ En Á. Valverde, «La poesía de Antonio Gamoneda (una lectura)», Cuadernos Hispanoamericanos, 522 (1993), p. 137.
} 
el yo lírico. Esta noción de impasse temporal la representa el mármol: «En la columna viva, / el fugitivo tiempo/ se detiene. [...]» (vv. 5-7). ${ }^{36}$

Exentos I (1959-1960 y 2003) continúa la evocación de este amor nostálgico de juventud. Es el único tiempo que se ha podido aprehender gracias al recuerdo, el resto escapan de la absorción de la muerte: «Ah verdadero amor, / qué sensación de tiempo/ poseído [...]» (vv. 5-7). ${ }^{37}$ El silencio del corazón lo preside. No obstante, ya empieza a aparecer la figura de la madre, a la que se va a encaminar pronto en un proceso de retracción hacia el arkhé. Blues castellano (1961-1966 y 2004) es culminación de la anterior etapa y un primer punto de inflexión. Del binomio yo y tú, que no desaparece del todo, vamos al nosotros, la solidaridad frente a la desgracia ajena a ritmo de blues y de gospel. No obstante, sigue sin vislumbrarse la esperanza. Las evocaciones de la infancia, de la madre, de la destrucción de la guerra y del desánimo de la posguerra se poetizan para mejorar un presente de impiedad.

Exentos II: Pasión de la mirada (1963-1970 y 2003) abriría el segundo ciclo en el que empieza la «retracción», palabra muy manida por la crítica gamonediana y por él mismo. ${ }^{38}$ El espacio y el tiempo se contraen para empezar el repliegue desde la injusticia histórica:

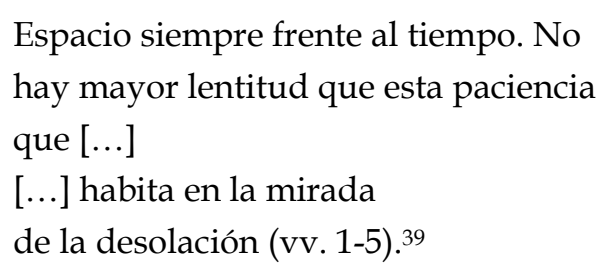

Asistimos a un espacio cóncavo, el del ser que se reabsorbe y que se abre hacia la muerte. Es un espacio invertido y teratológico, en el que animales extraños representan la depuración del yo ante el nuevo conocimiento. El tiempo gira su cronología lentamente desde este presente evocativo de un pasado frustrado hasta

\footnotetext{
${ }^{36}$ En Ibidem, p. 58.

${ }^{37}$ En Ibidem, p. 79.

${ }^{38}$ En Ibidem, pp. 173, 179, verbigracia.

${ }^{39}$ En Ibidem, p. 169.
} 
ese pasado ideal instalado en el olvido de la vida. Es la hipotética vuelta a un origen que desearía que se reiniciara la historia para poderla redirigir hacia una noción maniquea de un bien universal. Este proceso se muestra detalladamente en los cuatro siguientes poemarios que avanzan en espiral y que abren la técnica del fragmentarismo tanto en lo formal como en el contenido de escisión del ser en busca de su otro yo hacia la eternidad.

El primero es Descripción de la mentira (1975-1976 y 2003). En él ya estamos en un espacio de depuración somática y en un tiempo que fluye en dirección contraria a la cronología convencional en busca de la muerte en un pasado ideal. Para ello el yo lírico escenifica un itinerario trascendente similar al proceso de purgación, iluminación y unión que experimentan los místicos cristianos. El yo poético se evade de la historia y de la verdad social del franquismo en «Un país cerrado»,40 para entrar en el solipsismo de la ultrahistoria del ser en la época de la apertura democrática en «Un país sin verdad», 41 en referencia a la «verdad oficial impuesta». Busca al padre y a la madre en el momento de la mentira previa a la muerte en un pasado recreado del origen.

En este país, en este tiempo cuya pesadumbre se dibuja en lápidas de mercurio,

voy a extender mis brazos y a penetrar la hierba,

voy a deslizarme en la espesura del acebo para que tú me adviertas, para que me convoques en la humedad de tus axilas. ${ }^{42}$

Mi memoria es maldita. Más allá, antes de la memoria, un país sin retorno, acaso sin existencia:

$(\ldots)$

Era la exudación y penetraba el tiempo. Los insectos se fecundaban sin cesar y la serenidad nos poseía. Pero aquel tiempo no existió: sucedió en la inmovilidad como la música antes de su división. ${ }^{43}$

\footnotetext{
${ }^{40}$ En Ibidem, p. 178.

${ }^{41}$ En Ibidem.

42 En Ibidem, p. 175.

43 En Ibidem, p. 183.
} 
El segundo es Lápidas (1977-1986 y 2003). Su título es un signo disémico típico de Carlos Bousoño (Teoría) como puede ser el de la madre biológica y natural: su doble connotación alude a la muerte y a su carácter casi aforístico. Lápidas son también las frases con valor gnómico, apotegmático, sapiencial. En esta obra continúa ese descenso hacia la mentira redentora en la madre y ante la muerte. El espacio es interior y el tiempo se revierte, violentando la lógica tradicional. Ambos están presididos por recuerdos de infancia y presagios de muerte inminente. Gamoneda predica la redención de los oprimidos pero acaba descubriendo que «dios» tiene una máscara para ocultarse. Cuando esta cae, sólo se advierte el vacío: «Cae/ la máscara de dios: no había rostro./ ¿Quién habla aún al corazón amarillo?» (vv. 6-7).44 Es el silencio divino y una expresión de fe agnóstica. El origen se define por su ausencia, su invisibilidad y su incomunicabilidad y él no tiene semilla para reengendrar como la paz no tiene esperanza.

El tercero es el Libro del frío (1986-1992, 1998 y 2004). En él nos advierte en una clara referencia metapoética del tránsito espacial y temático (articulados desde la nostalgia al deseo inmanente) que se ha efectuado desde el primer ciclo poético hasta el segundo: «Hubo un tiempo en que mis únicas pasiones eran la pobreza y la lluvia./ Ahora siento la pureza de los límites y mi pasión no existiría si supiese su nombre».45 Se trata del mismo proceso en espiral que se va viendo en este y en los dos anteriores poemarios. Mientras se encamina hacia ese olvido el yo lírico se desdobla en el «vigilante de la nieve», una especie de alter ego, en la vejez y ante la muerte, que quiere volver al amor materno. Ese personaje o esa máscara del yo lírico fue inspirado por Jorge Pedrero, un obrero del vidrio y pintor que se suicidó, al que Gamoneda una vez se encontró diciendo solo que estaba cuidando de la nieve. Como bien afirma el poeta en El cuerpo de los símbolos: «No se equivocan plenariamente los críticos [...]: quizá alguna vez yo he sido o voy a ser el vigilante de la nieve».46 De la

\footnotetext{
${ }^{44}$ En Ibidem, p. 293.

45 En Ibidem, p. 335.

${ }^{46}$ En A. Gamoneda, El cuerpo de los símbolos, Murcia, Huerga y Fierro, 1997, p. 233.
} 
pobreza vamos hacia la pureza de los límites: «Alguien ha entrado en la memoria blanca, en la inmovilidad del corazón./ Veo una luz debajo de la niebla y la dulzura del error me hace cerrar los ojos./ Es la ebriedad de la melancolía; como acercar el rostro a una rosa enferma, indecisa entre el perfume y la muerte.»47

Son un tiempo y un espacio inexistentes que sólo cobran dimensiones en esa infancia estetizada y en los amores perdidos: «Esta hora no existe, esta ciudad no existe, yo no veo estos álamos, su geometría en el rocío./ Sin embargo, éstos son los álamos extinguidos, vértigo de $\mathrm{mi}$ infancia./ $\mathrm{Ah}$ jardines, ah números».48 Remembranzas de amores melancólicos que llevan a reflexiones sobre la dialéctica que dinamiza la creación y la existencia: el eterno ciclo del eros («tu lengua») y del tánatos («la sombra»). El uno, movimiento de perpetuación, no se puede entender sin el otro, el de destrucción y entrada a un nuevo estadio generacional. Son las dos caras del sempiterno movimiento cíclico de la vida.

\footnotetext{
Ha venido tu lengua; está en mi boca como una fruta en la melancolía.

Ten piedad en mi boca, liba, lame, amor mío, la sombra. ${ }^{49}$
}

La agonía se representa ante el muro que separa la muerte de la vida, ante el agua inmóvil y la blancura del final. Todo acaba sin esperanza en los líquenes del origen en lo invisible, en una nada en otra edad, la del origen, cuando el yo lírico arde con llama de depuradora pasión esotérica: «Ardes bajo las túnicas carnales./ Ha sido inútil la sutura negra:/ no hay agua en ti. Todas las fuentes manan en otra edad [...]» (vv. 1-3). ${ }^{50}$ Ello mientras va viendo cómo su último rostro desaparece y sólo hay luz ante sus ojos.

El cuarto y último libro de poemas es Arden las pérdidas (1993-2003 y 2004) en el que se insiste en ir a la muerte a través de la infancia, de la madre y de otro tiempo:

\footnotetext{
${ }^{47}$ En A. Gamoneda, op. cit., p. 338.

48 En Ibidem, p. 341.

${ }^{49}$ En Ibidem, p. 361.

${ }^{50}$ En Ibidem, p. 397.
} 
«Ahora mis ojos ven en el pasado: grandes flores inmóviles, madres atormentadas en sus hijos, líquenes fertilizados por la tristeza».51 Ese cronotopo se muestra con los líquenes de la suppa primigenia. Aparece un espacio rural dotado de toques místicos con luz y muerte. Luego hay sombras en los límites del crepúsculo, rostros que abandonan al yo lírico. Todo finaliza con la desaparición y el sucederse a sí mismo, reconociendo que la sabiduría total está en el olvido de lo histórico.

En la tercera fase se vuelve algo a la historia aunque deformado por el prisma de la extrañante luz de la revelación inmanente. Cecilia (2000-2004) vuelve a recuperar el amor en brazos de su nieta a la que ve ingresar en su madre en esa curiosa estética de la retracción. Es una parábola de ese proceso de reabsorción y posterior transformación del ser y de lo múltiple en lo uno. Está rodeada por esa luminosidad que precede a la muerte y que también puede venir después de ella. La vida es un hiato de oscuridad frente a esas dos posibles iluminaciones. Cecilia vive, para el yo lírico, en dos planos ya que le acompaña en el presente y es una encarnación de ese renacimiento en el pasado.

\section{Oigo tu llanto.}

Subo a las habitaciones donde la sombra pesa en las maderas inmóviles, pero no estás: sólo están las sábanas que envolvieron tus sueños.

¿Todo en mí es ya desaparición?

No aún. Más allá del silencio,

oigo otra vez tu llanto.

Qué extraña se ha vuelto la existencia:

tú sonríes en el pasado

y yo sé que vivo porque te oigo llorar. ${ }^{52}$

El presente, el pasado y el futuro se unen en el baile de generaciones en un espacio diluido de mística, amor y luminosidad. Es, como él nos dice, su «última flor» (v. 2) 53 que crece en ese pretérito ideal: «Esta hora no es tiempo; sólo existe el pasado/ y algunos rostros invisibles». ${ }^{54}$

\footnotetext{
${ }^{51}$ En Ibidem, p. 454.

52 En Ibidem, p. 494.

${ }^{53}$ En Ibidem, p. 510.

${ }^{54}$ En Ibidem, p. 516.
} 
En Exentos III (1990-2003 y 2004) ese pasado intemporal es el de un espacio agrario con sombras y luz invisible. Es el de la infancia en la que ya se está adentrando: «Esta hora no es tiempo; sólo existe el pasado/ y algunos rostros invisibles» (Ibid., p. 516). ${ }^{55}$ Como colofón, en Mudanzas (1961-2003) se apela a ese «dios» de justicia social con poca esperanza además de hacerse un recuento de plantas y comestibles relacionados con la magia que ayudan al hombre a encontrar potencialidades taumatúrgicas y visionarias en un diario apócrifo. Con esta técnica epistolar, el tono se convierte en uno más lírico y menos abstracto aunque con una forma erudita a modo de criterio de autoridad. Es interesante ver cómo se relacionan lo falsamente empírico con lo poético, y cómo la especulación intuitiva de este acaba subvirtiendo y violentando el discurso racionalista de aquel. Tal vez es el reconocimiento de que sólo desde fuerzas paranormales se puede cambiar o modificar una historia que la lógica ha destruido.

Con ello, su poética pretende ser un doble viaje, primero hacia el futuro, el del deceso, y luego hacia el pasado, un renacer para recomenzar la historia. Es un proceso cíclico ideal que se detiene en la frustrada experiencia del poeta con la inapelable muerte.

\section{EL SONIDO, EL SILENCIO Y LA PALABRA}

Como el mismo Gamoneda señala, lo poético es «el resultado de una interiorización de la realidad más intensa que ninguna otra» así como una «fuerza de representación de la realidad interiorizada». ${ }^{56}$ Es, así pues, un viaje que transita por las lindes entre lo íntimo y lo místico. Le da por tanto una carta de naturaleza autorreferencial, como simple canto, al lenguaje poético que lo aparta del lenguaje convencional. Es un canto de soledad y de convocación de una nueva realidad: lo ideal es que el logos deje de significar y se convierta en ser. Así describe a este tipo de

\footnotetext{
55 En Ibidem.

56 En A. Gamoneda, «Poesía y conciencia: notas de una revisión», Ínsula, 204 (1963), p. 4.
} 
poesía en Exentos I: «[...] la única poesía,/ es la que calla y aún ama este mundo,/ esta soledad que enloquece y despoja» (vv. 3-5). ${ }^{57}$ Este comentario metapoético lo opone a las ideas de transformación del mundo de Gabriel Celaya o de la «verdad práctica» como fin en sí misma de Louis Aragon y sus opuestas de Rafael Morales de una poesía que se justifique a sí misma tan sólo en la «belleza». Para él, el lenguaje lírico debe aspirar a romper con la escasez semántica del oficial. Mientras eso no suceda, el poder revelador del significante poético seguirá estando limitado por esa insuficiencia del significado. Así aparece en «Cuestión de instrumento» en Blues castellano:

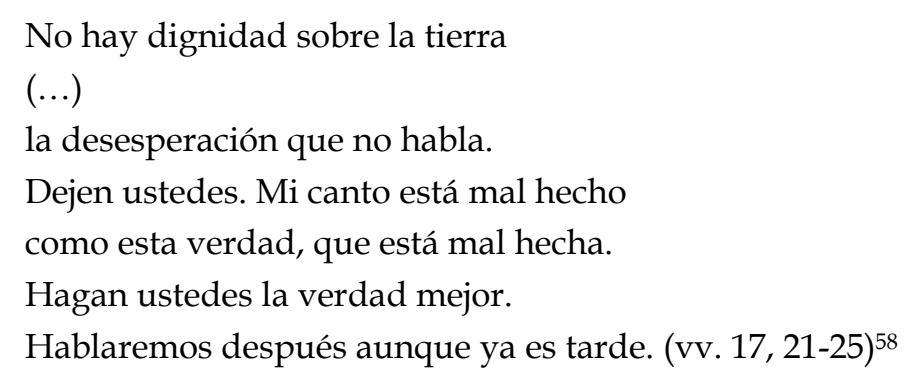

Estos versos nos conectan de nuevo con la idea de esa aspiración de pureza y de redención con un nuevo verbo ideal. Por otra parte, todo nuevo significante lingüístico supone la creación de nuevos significados. La realidad para Gamoneda está dentro del lenguaje ya que esa es una de las manifestaciones de la conciencia subjetiva a la que apela para llegar a una conciencia universal perfecta. No existe un referente objetivo ni tampoco un lenguaje unívoco. Por tanto, si se transforma el logos poético se puede pretender incluso alcanzar una nueva alternativa de dicción y de realidad que vayan más allá de lo que otros lenguajes literarios han podido expresar. Mientras la lírica no se consiga deslindar del lenguaje oficial denotativo y vacío, su capacidad connotativa sólo puede aspirar a violentar o a subvertir lo real, nunca a reemplazarlo. Ese tránsito intermedio anterior a la llegada de ese último lenguaje total, que aspira a depurarse hasta llegar a una palabra pura y originaria, es tan sólo un lenguaje revolucionario. Para ello parte del Orfeo negro de Jean Paul-Sartre: «[...]

\footnotetext{
57 En A Gamoneda, op. cit., p. 87.

58 En Ibidem, p. 97.
} 
cuando el oprimido sólo puede expresarse en la lengua del opresor, ésta se torna una lengua revolucionaria» (p. 159). ${ }^{59}$ Es una subversión del lenguaje del poder, tan exiguo en sus significaciones.

Por ello cabe decir que se articulan una serie de discursos a lo largo de su obra que están relacionados con esta evolución ideológica que él mismo marca. Desde Primeros poemas hasta Blues castellano se puede apreciar ese tránsito que va desde un tono intimista y evocativo hasta el acento más social, pero todavía en una lengua poética que usa un lenguaje más figurativo y menos metafórico que el que vendrá posteriormente. Es uno que sigue relativamente cercano al del opresor para comunicar el desasosiego interior frente a la historia al máximo número de lectores. Lo curioso es que cuanto mayor es su compromiso con la sociedad y con lo referencial, más impotente y frustrado se siente de revivirlo y de comunicarlo. A partir de Exentos II hasta prácticamente el final de su obra, la misma aporía sucede pero a la inversa. El lenguaje se altera para captar y crear nuevos significados que sólo son descifrables por minorías formadas literariamente, no tanto por el gran lector. No obstante, es entonces cuando él busca con más anhelo un reencuentro con el otro desde la inmanencia. Quiere que la historia recomience, aunque lo vea extremadamente difícil, y por ello anhelaría una nueva palabra y discurso que puedan dar los elevados significados de una justicia universal. Ellos son irrepresentables dada la limitada naturaleza del lenguaje que existe, pero se metaforizan desde la música («música de los límites» en Libro del frío: v. 3)60, el silencio y los signos abstrusos («signos (...) vacíos» o «palabras incomprensibles» en Arden las pérdidas: vv. 1-5). ${ }^{61}$

\footnotetext{
59 En A. Gamoneda, «Sobre Nazim Hikmet, los negro spirituals y mi Blues castellano» en AAVV, Antonio Gamoneda, AAVV, Madrid, Calambur, 1993, p. 159. (También en El cuerpo de los símbolos, pp. 81-98).

${ }^{60}$ En op. cit., p. 372.

${ }^{61}$ En Ibidem, p. 415.
} 
Véase ese valor de lo musical como revelación después de la muerte en Sublevación inmóvil:

\author{
Cantidades de tiempo \\ sitúan cantidades \\ de sonido. Escucho \\ más allá de la muerte. \\ La música se alza \\ de un pozo de silencio; \\ es labranza del aire \\ en tímpanos de fuego \\ y ha entrado en mí. Ahora es \\ música mi pensamiento. ${ }^{62}$
}

$\mathrm{O}$ en este iluminador fragmento de vaciamiento interior y de llegada a la plenitud órfica en la inmaterialidad del silencio de Descripción de la mentira: «Escuché hasta que la verdad dejó de existir en el espacio y en mi espíritu,/ y no pude resistir la perfección del silencio». ${ }^{63} \mathrm{O}$, por último, en este otro extraído de Lápidas, situado en la iluminación no de la unión, sino de la muerte. Es un espejismo antes de llegar a un oasis de extinción personal: «Aquel aire entre el resplandor y la muerte se hace sustancia que no alcanzan a borrar los días y los vientos. El contenido de la edad son estos lienzos transparentes. Signos exactos e incomprensibles. Están en mí con el valor de una llaga; algunas cifras arden en mis ojos».64

Por consiguiente, en su obra la palabra se va haciendo cada vez más conceptual y el discurso entero se atomiza para intentar captar esa nueva realidad que se resiste a aparecer ya que reside en los espacios en blanco entre los poemas. A saber, es el lector el que va a ir completando ese rompecabezas conceptual con su arbitraria descodificación semiótica. Este proceso de disgregación es paralelo al de desintegración del ser frente a la gnosis. De una expresión lírica y más testimonial vamos a otra más abstracta y sintética del mismo modo en que del cuerpo se escinde la psique y finalmente se reabsorbe en esa búsqueda identitaria. Es el movimiento

\footnotetext{
62 En Ibidem, p. 68.

${ }^{63}$ En Ibidem, p. 173.

${ }^{64}$ En Ibidem, p. 253.
} 
iluminativo que va de una purgación personal a una unión interior que nunca se producirá completamente en su obra. Lo importante es ver la riqueza de la imaginería y de las metáforas para expresar la inefabilidad del trayecto ideológico y poético que se emprende. Gamoneda, en pocas palabras, es heredero de la amarga autorreflexividad de que hicieron gala los místicos de la Cábala, del Sufismo o del Cristianismo en la España medieval a la hora de expresar lo intangible de la percepción esotérica. Esa falta de significantes, así pues, se suple con ese nuevo lenguaje que, en contra de lo que se piensa, no es conservador (no en vano se aparta del poder) sino progresista (ya que pretende un cambio en el pensamiento, en la historia y en la realidad).

Veamos cómo formula esa palabra originaria redentora en Libro del frío:

Hay un muro delante de mis ojos.

En el espesor del aire hay signos invisibles,

hierba cuyos hilos entran al corazón lleno de sombra,

líquenes en el residuo del amor. (vv. 1-4) ${ }^{65}$

Finalmente, otro aspecto importante que conviene destacar es el papel del silencio. Es el resultado de la desarticulación del lenguaje convencional y de su expansión en los territorios de un conocimiento pararracional. Para construirlo, se busca esa palabra depurada que remite, en balde, a la primera palabra del lenguaje, la ideal de abolengo verlainiano o juanramoniano. El hecho de que el silencio represente todo aquello que los sentidos humanos no pueden percibir, esa realidad oculta que nos puede ayudar a conocer mejor la verdad, no implica que sea completamente inmaterial. Está antes o más allá de la percepción del hombre, pero en él reside toda una ciencia del destino. Tiene un poder convocador de nuevos sonidos y palabras, los del origen. En él espera la madre para introducir de nuevo al yo lírico en su seno y hacerle renacer. En la misma obra, nos lo muestra de este modo en los dos siguientes fragmentos:

\footnotetext{
${ }^{65}$ En Ibidem, p. 375.
} 
Hablan los manantiales en la noche, hablan en los imanes del silencio.

Siento la suavidad de las palabras olvidadas. (p. 340) ${ }^{66}$

$[\ldots]$

La mujer cuyo corazón es azul y te alimenta sin descanso,

ésa es tu madre dentro de la ira;

la mujer que no olvida y está desnuda en el silencio,

ésa fue música en tus ojos.

Vértigo en la quietud: en los espejos entran sustancias corporales y arden palomas. Tú dibujas juicios y tempestades y lamentos.

Así es la luz de la vejez, así

la aparición de las heridas blancas. (vv. 6-12) (77 $^{67}$

\section{LA MADRE COMO LOCUS ORIGINARIO}

Nos dice Álvaro Valverde que su obra «es un discurso circular: va y vuelve sobre la memoria cíclicamente» 68 para recuperar, depurar y reformar un origen personal y colectivo a través de la obsesiva figura de la madre y de la ausencia paterna: «Toda ella se debe a una estética de la retracción que va de lo real o exterior (despojamiento, brevedad, ajuste, intensidad, cortedad, elipsis) a lo simbólico o interior (vuelta a lo materno, a lo original, a lo primario)». ${ }^{9}$ Es un problema de identidad porque siente que no tiene «padre ni especie» (v. 1) en Exentos $I I,{ }^{70}$ ya que fue privado de esa figura cuando era un niño. Esta carencia le ha castrado emocionalmente y le ha conducido a ese deseo edípico de volver a la placenta materna representada por las aguas del mar y de la muerte. La madre, por ende, deviene en un centro desde el que se va a irradiar la vida del nuevo ser y del nuevo cosmos, y sus aguas simbolizan las de la suppa primigenia desde la que se originó la vida. Como bien dice Armando López Castro: «El símbolo de la madre asume el

\footnotetext{
${ }^{66}$ En Ibidem, p. 340.

${ }^{67}$ En Ibidem, p. 374.

68 En Á. Valverde, «La poesía de Antonio Gamoneda (una lectura)», Cuadernos Hispanoamericanos, 522 (1993), p. 135.

${ }^{69}$ En Ibidem, p. 137.

70 En A. Gamoneda, op. cit., p. 145.
} 
valor de un arquetipo y nos devuelve al tiempo de los orígenes, que la poesía busca una y otra vez».71

Las resonancias cristianas tanto en la religión como en el arte son evidentes en su obra: la imagen de la pietà o del stabat mater enfrente de la cruz. La obra de Gamoneda se centra y se recrea en el dolor y por ello podemos considerarla, sobre todo desde Exentos II, como un martirologio, como una penitencia mortificatoria del yo lírico. De esta manera, se produce una purificación de este ser en su llegada al momento cúspide de la desaparición. Allí, la madre recupera y reengendra al hijo y le da nueva forma como una generación más en sus descendientes. De todas formas, recordemos que el sentido trascendente está ausente en esta obra. Es un deseo de evocar una arcadia perdida en la que la inocencia blindaba al sujeto frente a la turbamulta del mundo. El canto del origen es un deseo de olvidar la locura del mundo real, que usa a los individuos y que tan pragmática como cínicamente se hace llamar como «razón de estado», para articular un espacio maternal de resonancias telúricas. Esperanza Ortega lo pone en estos términos: «Es la voz de la tierra, la voz del origen, la voz de lo material y maternal».72

Psicológicamente hablando, es un proceso de anclaje para situar a un ser descentrado ante la angustia frente a la muerte que se siente como inminente. La neurosis de insatisfacción vital, amatoria y erótica que preside las páginas de sus poemarios es la causa de esta obsesión. Es una fobia de anticipación ante algo que se sabe que ha de llegar: el final de la vida. Por ello, el estro literario de Gamoneda se convierte en una manera de sublimar el horror ante lo perecedero, una manera de justificar la existencia y de pretender perpetuarla mediante la palabra. Asimismo, la vuelta a la madre no sólo es un ideal de resurrección, sino también algo más cercano:

\footnotetext{
${ }^{71}$ En A. López Castro, «Antonio Gamoneda: la poesía de la memoria», en Voces y memoria. Poetas leoneses del siglo XX, Valladolid, Junta de Castilla y León, 1999, p. 161.

72 En E. Ortega, «La música de la oscuridad. Antonio Gamoneda», Campo de Agramante, 5 (2005), p. 109.
} 
la protección, el ser benefactor que no pide nunca cuentas a sus hijos de sus errores, el abrigo frente a la injusticia y a la soledad, la única que lo perdona todo con sinceridad.

En el poema «Hablo con mi madre» de Blues castellano el poeta le pide que le muestre de nuevo la tierra de la que él procede. La madre biológica y la naturaleza se funden en una clara alusión de resonancias panteístas:

He sentido tus manos.

Perdido en el fondo de los seres humanos te he perdido como tú sentías mis manos antes de nacer.

Mamá, no vuelvas más a ocultarme la tierra.

Ésta es mi condición.

$$
\text { Y mi esperanza. (vv. 14-19) } 73
$$

En Descripción de la mentira se alude a esa reversión del viaje interior hacia el pasado con el arquetípico término de Gamoneda, y de sus críticos, denominado «retracción». Este movimiento reversivo es el que va a vertebrar el desarrollo de la «diégesis» poética desde el principio de su obra hasta prácticamente el final: «[...] mi obra es la retracción, la retirada hacia una especie maternal». ${ }^{44}$ En la misma obra, de manera metonímica, se alude a ese génesis desde los pezones de los senos maternos. Es la época de lactancia, el alimento líquido con el que se inicia la vida tras el de la placenta. Así pues, una serie de distintas «aguas» se acaban reuniendo para regenerar al ser y llevarlo hacia una raza superior de hombres que manifiesten esa supremacía al valorar su radical igualdad en derechos y en deberes: «[...] si yo despierto y tus pezones manan sobre mi boca y no sé tu nombre y me alimentas antes de abandonarme,/ mi respuesta entra en ti y existe el tiempo como una reunión de aguas: estoy en ti y no he temido tu desaparición./ [...]/ Yo estoy naciendo en otra especie $[\ldots] » .^{75}$

\footnotetext{
${ }^{73}$ En A. Gamoneda, op. cit., p. 125.

${ }^{74}$ En Ibidem, p. 179.

${ }^{75}$ En Ibidem, p. 187.
} 
El recuerdo le lleva a ver cómo se acabó la inocencia y empezó la historia de injusticia de la que se trata de huir. La salida por la vagina materna dilatada y la sequedad de los pechos maternos son los últimos momentos en que el yo lírico era libre y puro. Es una invitación a empezar por allí otra vez: «[...] y los muslos que yo conocí con mi lengua se cerraron y los pezones que estuvieron en mis labios se endurecieron como sílice». ${ }^{76}$ Asimismo, en su obra se alude a que el renacimiento se ha de producir desde las aguas. Ellas tienen un doble significado: el de la charca originaria de la que nació la vida y el líquido amniótico materno, simbolizados también por la presencia de los «líquenes»,77 de los «légamos», ${ }^{78}$ de las «aguas inmóviles»79 o de las «aguas coléricas». ${ }^{80} \mathrm{El}$ «tú» tanto se puede referir al padre como a la madre ya que el poeta va dirigiéndose a ellos sin dar previo aviso. Es interesante esta estrategia andrógina: nos muestra las dos caras de un mismo ser, lo masculino y lo femenino: «Tu voz en dátiles sangrientos surge de las sustancias distribuidas sobre el mar $[\ldots]]^{81} \mathrm{o}$ «Días de labranza extendidos más allá de las aguas/ [...]/ así es el mundo delante de mis ojos». 82

La figura de la madre, en ese proceso de abstracción paulatina que va sufriendo su obra, se va ahuesando, se convierte en un puro espectro, en un motor de vida sin figura. El carácter surreal de la obra, clara deudora de ese movimiento vanguardista, como toda mística moderna, se incrementa en Lápidas: «Madre indistinta, líbrame de quien se oculta entre palomas, cubre mi rostro, sálvame del viernes» (v. 3). ${ }^{83}$ Así se expresa en el Libro del frío, en donde el paso de la existencia a la inexistencia, un ciclo de generación, destrucción y regeneración, está marcado por esta figura anfibológica: «La inexistencia es hueca como las máscaras y su visión es

\footnotetext{
${ }^{76}$ En Ibidem, p. 192.

${ }^{77}$ En Ibidem, pp. 173, 386, verbigracia.

${ }^{78}$ En Ibidem, p. 180.

${ }^{79}$ En Ibidem, p. 232.

${ }^{80}$ En Ibidem, p. 244.

${ }^{81}$ En Ibidem, p. 189.

82 En Ibidem, p. 203.

83 En Ibidem, p. 246.
} 
lívida, pero tú oyes el grito de las madres del agua y acaricias los ojos que vieron la inexistencia».84 En Arden las pérdidas se identifican las aguas con la muerte y el renacer en la vulva materna, que recordemos que es también una encarnación de la mandorla en donde está el pantocrátor cristiano iluminando la creación del mundo. Es ese punto de intersección entre la tierra y el cielo, lo inmanente y lo trascendente, el día y la noche, lo material y lo espiritual o lo masculino y lo femenino: «Vi la vagina maternal que llora y el dolor en una cuenca dorada [...]» (v. 2). ${ }^{85}$ La vida convencional, la muerte y la vida eterna se funden en un punto en la totalidad de la visión poética:

\author{
Miro mi desnudez. Contemplo \\ la aparición de las heridas blancas. \\ Envuelto en sábanas mortales, \\ bebo en las aguas femeninas \\ la dulzura y la sombra. ${ }^{86}$
}

Como colofón, en Cecilia le acaba recomendando a su nieta, la cual le devuelve fugazmente la ilusión por la vida, que vuelva hacia su madre como símbolo de perpetuación de la especie a través de la mujer: «Entra en tu madre y abre en ella tus párpados,/ entra despacio en su corazón./ Vuelve a ser fruto en el silencio». [...] (vv. $1-3) .87$

\title{
5. CONCLUSIONES
}

En conclusión, aunque lo niegue, Antonio Gamoneda está siguiendo los patrones de la mística sincrética cuando construye su entramado poético. Esta vuelta al pasado ideal para recomenzar la Historia y esta dislocación de las nociones convencionales de Dios («dios» para él, y para su amigo José Ángel Valente), ser inmanente, tiempo en reversión y espacio interior, ambos de la conciencia, además de las de una palabra y de una madre originarias, pretenden buscar un modelo

\footnotetext{
${ }^{84}$ En Ibidem, p. 357.

${ }^{85}$ En Ibidem, p. 421.

${ }^{86}$ En Ibidem, p. 426.

87 En Ibidem, p. 491.
} 
idealista de «justicia social». Esa justicia se postula en un más allá tan difícil de alcanzar como en nuestro mundo real. Su obra en general es una corrección postmoderna a la globalización, al hiperconsumismo y a la desnaturalización de la realidad por parte de la cultura de masas. Es también un alegato en contra de los desórdenes, abusos y corruptelas del poder y de su sometimiento de los libres impulsos individuales en la historia. Frente a ellos, se erige la evasión esotérica del yo lírico en esta poesía de conocimiento interior. La única «verdad» para nuestro poeta es la muerte y la «mentira» es una ilusión de eternidad que no se llega a plasmar en esta obra por insuficiencias del lenguaje y de nuestro conocimiento. Tal vez, estos últimos versos del Libro del frío son lo máximo que ha podido captar su diapasón poético: «[...]/ es la agonía y la serenidad./ Quizá soy transparente y ya estoy solo sin saberlo. En cualquier caso, ya/ la única sabiduría es el olvido».88

\footnotetext{
${ }^{88}$ En Ibidem, p. 475.
} 


\section{BIBLIOGRAFÍA.}

AAVV., Antonio Gamoneda, Madrid, Calambur, 1993.

BOUSOÑO, C., Teoría de la expresión poética (hacia una explicación del fenómeno lírico a través de textos españoles), 2 vols., Madrid, Gredos, 1985.

BRUNS, G., Modern Poetry and the Idea of Language: A Critical and Historical Study., New Haven and London, Yale University Press, 1974.

CANDAU, A., «Antonio Gamoneda: la conciencia y las formas de la ironía», Hispanic Review, 62.1 (1994), pp. 77-91.

CASADO, M., «Un ejercicio de comparación: “Lapidario” y “Lápidas”» en AAVV, Antonio Gamoneda, Madrid, Calambur, 1993, pp. 119-134.

CASTRO FLÓREZ, F., «Manos de tierra» en AAVV, Antonio Gamoneda, Madrid, Calambur, 1993, pp. 29-48.

COLINAS, A., «Lápidas, de Antonio Gamoneda: un humanismo para el fin de siglo», Ínsula, 487 (1987), pp. 16-17.

DEBICKI, A., Poetry of Discovery: The Spanish Generation of 1956-1971, Lexington, Ky, The University Press of Kentucky, 1982.

_. Historia de la poesía española del siglo XX: desde la modernidad hasta el presente, Madrid, Gredos, 1997.

DIEGO, J. M., «Antonio Gamoneda, el valor de la marginalidad», Ínsula, 543 (1992), pp. 11-12.

DONCEL, D., «Las experiencias de Antonio Gamoneda» en AAVV, Antonio Gamoneda, Madrid, Calambur, 1993, pp. 9-16.

GAMONEDA, A. y F. R. DE LA FLOR (eds.), «Preliminar» en Sílabas negras, Salamanca, Ediciones Universidad de Salamanca y Patrimonio Nacional, 2006, pp. 7-96.

GAMONEDA, A., Esta luz: poesía reunida (1947-2004), Epílogo de Miguel Casado, Barcelona, Galaxia Gutenberg-Círculo de Lectores, 2004. 
. «Poesía y conciencia: notas de una revisión», Ínsula, 204 (1963), p. 4.

. «Sobre Nazim Hikmet, los negro spirituals y mi Blues castellano» en AAVV, Antonio Gamoneda, AAVV, Madrid, Calambur, 1993, pp. 145-159. (También en El cuerpo de los símbolos, pp. 81-98)

_. El cuerpo de los símbolos, Murcia: Huerga y Fierro, 1997.

_. Valente: texto y contexto. Santiago de Compostela, Universidade de Santiago de Compostela, 2007.

GARCÍA JAMBRINA, L. (ed.), La promoción poética de los 50. Ángel González, José Manuel Caballero Bonald, Carlos Barral, José Agustín Goytisolo, Jaime Gil de Biedma, José Ángel Valente, Francisco Brines, Claudio Rodríguez, Madrid, Espasa Calpe, Colección Austral, 2000.

HASSAN, I., The Postmodern Turn: Essays in Postmodern Theory and Culture, Columbus, Ohio State University Press, 1987.

HEIDEGGER, M., Ser y tiempo, Traducción, prólogo y notas de Jorge Eduardo Rivera C., Madrid, Trotta, 2003.

JAMESON, F., Postmodernism, or, The Cultural Logic of Late Capitalism, Durham, Duke University Press, 1991.

LÓPEZ CASTRO, A., "Antonio Gamoneda: la poesía de la memoria», en Voces y memoria. Poetas leoneses del siglo XX, Valladolid, Junta de Castilla y León, 1999, pp. 151-189.

LYOTARD, J. F., The Postmodern Condition, 1979, Translated from French by Geoff Bennington and Brian Massumi, Minneapolis, University of Minnesota Press, 1993.

MARTÍNEZ, S., «Antonio Gamoneda: “La poesía sirve para nombrar lo desconocido".», Lateral, 83 (noviembre 2001), pp. 8-9.

MARTÍNEZ GARCÍA, F., Gamoneda, una poética temporalizada en el espacio leonés, León, Universidad de León, 1991. 
MAYHEW, J., «Rhetoric and Truth in Gamoneda», in The Poetics of Self-Consciousness. Twentieth Century Spanish Poetry, Lewisburg, Bucknell University Press, London and Toronto, Associated University Presses, 1994, pp. 80-95.

MESTRE, J. C., «Sublevación inmóvil» en AAVV, Antonio Gamoneda, Madrid, Calambur, 1993, pp. 87-94.

MIRÓ, E., «Una colección y dos poetas: José Antonio Gabriel y Galán y Antonio Gamoneda», Ínsula, 377 (1978), pp. 6-7.

MOLINA, C. A., «Dos visiones épicas de lo contemporáneo», Camp de L'Arpa, 84-85 (1981), pp. 65-67.

ORTEGA, A., «La realidad plástica en Descripción de la mentira» en AAVV, Antonio Gamoneda, Madrid, Calambur, 1993, pp. 109-117.

ORTEGA, E., «La música de la oscuridad. Antonio Gamoneda», Campo de Agramante, 5 (2005), pp. 101-115.

PÉREZ LASHERAS, A., «De la juventud del dolor a la frialdad de la existencia: la poética unitaria de Antonio Gamoneda» en Luis Beltrán Almería y Juan Carlos Pueo (eds.), Actas del Congreso Jaime Gil de Biedma y su generación poética, Vol. II, Zaragoza, Diputación General de Aragón, 1996, pp. 655-664.

PUERTO, J. L., «El animal de la memoria» en AAVV, Antonio Gamoneda, Madrid, Calambur, 1993, pp. 17-27.

RODRÍGUEZ, I., «Una conversación con Antonio Gamoneda» en AAVV, Antonio Gamoneda, Madrid, Calambur, 1993, pp. 61-85.

RODRÍGUEZ PADRÓN, J., «Desnudo ante el agua inmóvil» en AAVV, Antonio Gamoneda, Madrid, Calambur, 1993, pp. 135-144.

SERRANO, P., «Gamoneda: la escasez y la necesidad», Letras Libres, 84 (2005), pp. 8487.

SILVER, P., La casa de Anteo: Ensayos de poética hispana (De Antonio Machado a Claudio Rodríguez), Versión española de Salustiano Masó, Madrid, Taurus, 1985. 
SUÑÉN, J. C., «La expresión de un deber desconocido (Poesía y conciencia en Blues castellano)» en AAVV, Antonio Gamoneda, Madrid, Calambur, 1993, pp. 95102.

VALENTE, J. Á., Obra poética, 1999, 2 Vols., Madrid, Alianza, Vol 1, $2^{a}$ reimpresión, 2000; Vol. 2, 3ª reimpresión, 2001.

VALVERDE, Á., «La travesía del silencio (Pasión de la mirada)» en AAVV, Antonio Gamoneda, Madrid, Calambur, 1993, pp. 103-108.

_. «La poesía de Antonio Gamoneda (una lectura)», Cuadernos Hispanoamericanos, 522 (1993), pp. 134-142.

VILAS, M., «La muerte, y su hermano el miedo: la "edad" de Antonio Gamoneda» en AAVV, Antonio Gamoneda, Madrid, Calambur, 1993, pp. 49-60. 